\title{
On the Famous Painting "Search Every Lofty Peaks for Draft" in the Record of Shi tao Drawing Theory
}

\author{
Jinsong Li \\ College of Fine Arts, Tonghua Normal University, Tonghua, Jilin, 134002, China
}

Keywords: Shi Tao, Record of drawing theory, Lofty peaks, Draft

\begin{abstract}
Shi Tao (Kugua monk) was a famous calligrapher and painter in the late Ming Dynasty and early Qing Dynasty in China, and also was a theorists with self-views. In the various aspects of painting art ideas and techniques he had superb views, in the theory he had a complete set of theoretical system. The paper through research on the artistic characteristics and techniques of the scroll "search every lofty peaks for draft" to reflect the realistic significance and far-reaching impact in modern Chinese painting.
\end{abstract}

\section{Kugua monk -- A Chinese painting master}

In late Ming and early Qing Dynasty landscape painting the most innovative painter must be Shi Tao, so called Kugua monk as a great master of Chinese painting is not excessive. Wu Guanzhong respects Shi Tao as the father of Chinese modern art, his artistic creation was two centuries early than Cezanne.

Shi Tao's paintings were calligraphic freely, took off as a stereotype, and with unique style, and his articles and poetry were also out of the ordinary, which was named "three incomparable". He was not only unique in creation practice, but also very insightful in the painting theory; "the record of Shitao drawing theory" was called the classic of Chinese painting aesthetics.

From the Wei and Jin Dynasties to the Ming and Qing Dynasties, Chinese landscape painting development had been flourishing, and techniques were also fully mature. In early Qing Dynasty painting, the most personality and the most vitality were reform school of painting took "four monks" as the representative. The greatest impact on future generations was Shi Tao. Among the Ming and Qing Dynasties painting masters, Shi Tao's opposition to the ancient was particularly evident; when young he wrote a special momentum extraordinary painting postscript. With a very rebellious spirit Shi Tao presented in Qing Dynasty painting cycle which very popular to imitated ancient style.

Shi Tao put forward for many times in his life, which was to bold innovation by subject's own feelings, and not copy of nature and imitation of the ancients. So, for those pedantic, he showed the highest contempt. But Shi Tao was not blind against all laws, he pointed out that painters should follow certain rules in the painting creation, if you did not follow certain rules, then the painting might become doodle without any constraints. Nothing can be accomplished without norms or standards; you have to understand the law of painting if you want to paint. Shi Tao thought that "rules from painting" the rules were from nature, rather than "rules from the ancients", the mission of artists also not to repeat the ancient rules. He had always stressed to by ancient rules to create now, and against the ancient rules for rules.

At that time, because personality of Shi Tao's painting style was too strong, was thought brotherhood habits by the majority of artists. But he had a good opinion of his paintings. "I have no means, later there will be bosom friend." Just as Shi Tao said, shortly after his death, Yangzhou eight strange painters rised who influenced by him. And more to the future, the impact became greater. Especially in the modern China, Shi Tao's influence was very influential. Broke the traditional norms, bold innovation, emphasizing the performance and expression of the main consciousness, rose the people consciousness to draw consciousness, from this point of view, some western Chinese art history scholars took Shi Tao as the beginning of Chinese modern art history, that was really make sense. 


\section{Search every lofty peaks for draft}

"Search every lofty peaks" in take nature as teacher. In the "four monks", travelled the most was Shi Tao. He advocated taking nature as teacher, Shi Tao poem: "Huangshan Mountain is my teacher; I am Huangshan Mountain's friends, million classes in my heart, Huangshan Mountain without exception."

With consistent love and respect to the natural mountains and rivers, Shi Tao visited a place must draw, to reflect Huangshan such bizarre and magnificent mountain, blindly used ancient Chinese painting techniques could not handy with facility, so Shi Tao had a great view and searched lofty peaks in all life.

In the life of Shi Tao, the most description was Huangshan Mountain. During the period in Xuancheng City, he had visited Huangshan Mountain for three times, every time travel and memory made him very excited. All people who visited Huangshan Mountain would feel amiable at the sight of his "Huangshan Mountain Drawing". Shi Tao put forward, the landscape painters should take nature as teacher, landscape painter only personally feel the beauty of nature, personally percept the entelechy and vitality of the nature can create superb landscape masterpiece.

"Draft" is the creation stage. More than ten years in Xuancheng City was a critical period for Shi Tao style. In this period, Shitao's landscape paintings basically were not out of Xuancheng School like Mei Qing as the representative, and themes showed mostly Jingting Mountain, Huangshan Mountain. He repeatedly visited Huangshan Mountain, enjoyed wonderful sceneries as peaks, grotesque rocks, the sea of clouds, and typical revealed the really appearance and true nature of Huangshan Mountain, even local people Mei Qing visited Huangshan Mountain after seeing the paintings of Shi Tao, and in his paintings also received a lot of inspiration. Mei Qing very admired on Shi Tao's painting ability, especially for Shi Tao aesthetic ability of the grasp and performance on natural beauty of Huangshan Mountain.

In Shi Tao"s life, he described the most scenic was Huangshan Mountain, such as "Huangshan Drawing" scroll, "the landscape book", "the voiceless landscape drawing" scroll, etc., the best known was the "search every lofty peaks drawing" volume, to indulge in sway style and strengthen the Wang Meng dense body paining style. He collected the pure of traveled mountains, volume tail there was the painter's self - consciousness, affirmed the Northern Song Dynasty Guo Xi's landscape painting advocated creation theory of "expected", "tour", "home", and emphasized the painter should have the sense of innovation.

After careful research and eclectic of the ancient techniques, the venation of Shi Tao's painting theory was gradually clear, techniques were becoming more and more mature, thus finally entered the realm "without rules, that is the rule", created a dissolute, free and easy artistic style. Basically the year 1680 could be a demarcation point, and Shitao truly entered the mature period of art.

As Shi Tao enjoyed wandering the scenic spots around the country, in his pen continuously appeared "Huaiyang clean autumn drawing" scroll depicting Huaiyang, "the Huishan drawing" framing in Wuxi, "viewing mountain in Yuhang rawing" volume in Northern Zhejiang.

\section{The use of "search every lofty peaks for draft" in Shi Tao's landscape painting}

The idea "search every lofty peaks for draft" is also the essence of Chinese traditional painting, that is the artists collect material in life, and express material artistically.

A new approach of "advocate conception" and with rules broke the old program.The meaning of "conception" is not the same in different times, and it is the common pursuit of literature and art in ancient China, at the same time with the same aesthetic value and character. In traditional Chinese painting and calligraphy "conception before write or paint" was a common requirement.

Shi Tao's novel composition of painting style, whether the ink Jiangnan or Huangshan Mountain clouds or cliffs, dead tree and jackdaw, or profound, lofty, and flat scene layout were novel and unique style. He was good at the "intercept method" with the characteristic scene to convey the profound emotion. He continued to innovate his painting style, and constantly renovated his painting artistic conception. Some paintings took panoramic picture to express the wide scene; some paintings 
deeply depicted the part, and depicted the scene vivid and highlight. Shi Tao's distinctive style emphasized the comparison of simple and complex, the simple place was simple to blank, the complicated place was in-depth depicted things. With this strong contrast to produce a flat partition of the painting, and made full use of simple and complex area to make the painting very coordinated. Adopted the way of inscription to coordinate blank space and rich content and formed contrast, adopted density, structure and form to operate position, and made the paintings totally natural.

Shi Tao also paid attention to the expression of its momentum. He used bold writing on the Xuan paper and brushed with dripping momentum. His works were good at bold and unconstrained, had a great influence on Chinese painting especially in landscape painting. "Yunshan Mountain drawing scroll" grasped view from the middle part. Highlighted the momentum of cloud. He used the "one water and two shores style" way to make the paintings static in moving, virtual in reality. Shi Tao's composition was not only the form of operating positions, and the conception in Shi Tao's works reflected of Shi Tao's point of view on composition; Shi Tao's "voiceless landscape drawing", the whole picture was very magnificent, beautiful and harmonious, was the representative of "search every lofty peaks for draft". It was also the essence of Shi Tao painting theory.

In the composition Shi Tao made such a prominent achievements, because adhered to the "search every lofty peaks for draft", south Anhui painters took Huangshan Mountain as teacher, the traditional the pursuit of strange, surprise and appalling art of composition was flourish in the hands of Shi Tao. The help of mountains and rivers, the forces of nature, and Shi Tao' gifted talent, created amazing landscape paintings.

Hurry and relax in order, variable dry and wet, different thickness, eight out of the front on painting. Shi Tao's unique style of landscape painting was still in variable painting techniques, which is difficult to speculate.

"Voiceless landscape drawing" was painted by Shi Tao when left Xuancheng to Jinling Changgan temple to recuperate. The painting descripted Shi Tao and his friends enjoyed the cool and recited poems in pavilion in the quiet and natural environment. He made very carefully depict for the wondrous pines, crags, miscellaneous trees and other scenic. Texturing method did not rigidly adhere to the original program, combined the various texturing method together as changpima, duanpima, heye, zhedai, jiesuo etc., took vividly describe the objective things as the criterion. With a strong ink dot coating, which was quite natural. This can be said the representative work Shi Tao transformed from the early phase to the middle phase; "the house of the sea" was painted in Nanjing by Shi Tao. This painting was more calm and like Wang Meng, with dry and pine brush with hook, order of priority, free and easy changeable, gloomy and vast, shallow set colors; "the boat cliff and giant gully drawing" was a rare huge boutique by Shi Tao. The painting was vigorous and smart, deep and big-hearted, color changeable, moss dot strong and vivid, easy to increase feeling of vigorous and magnitude of the picture.

It is worth noting, there were very weird works when Shi Tao in middle age, the United States Wang Jiqian possession of an open "landscape book", not stick to one pattern of landscape painting, with painting with thick lines, and most lines sharp folding, arbitrary sway, composition between points and lines as shade, thickness, assembling and parting was modern sense. This style of painting both in painting circle at that time and in his works were very rare, in the atmosphere when the majority of landscape mere gravel pile, his painting style seemed singularly beautiful.

The appreciation and analysis of representative "search every lofty peaks for draft". In Xinwei year of Kangxi Dynasty thirty years, Shi Tao painted "search every lofty peaks for draft" scroll for Shen'an who was the master of Qiehanzhai. This scroll was on behalf of his late period, was criticism on the flagging painting style on that time.

On the front cliff stacked together, in the middle layer many hills fluctuated around, the mountains and rocks odd staggered. The stream in mountains swirled into the river. A mountain standed in the center of river on the end. The whole volume of grand pomp was in the middle of a creative painting mood. Solid and dignified lines drawed the outline of peaks, dense texture on rocks, and coiled together staggered, with strong painting. Mountains covered with moss dot, there were a sparse dense, strong and weak, wet and dry, open and joint, not only without feeling of forced plug and with 
thousands of million points, points out the heavy peak rock column, the mountains hidden. The whole volume was grand pomp in the middle of a creative painting mood, the full piece of paper were the world of points, component was very much without the feeling of stagnation and turbid compaction, because the moss points and tree and stone's structure and motive force were organically combined.

Shi Tao wrote a comment article in the end of the painting, which had his own special meaning. For the people with subjective imagination proposed severe criticism, showed his emphasis on the objective reality, to implement the consistent proposition took actual landscape scenery as a teacher; he advocated a profound innovation of landscape and against blindly imitated ancient and modern painting techniques.

\section{Make "search every lofty peaks for draft" serve the present}

The whole art world thinks Chinese landscape painting from classical to modern, Shi Tao is a bridge. Therefore, Wu Guanzhong believed that the "Shi Tao is the starting point of the Chinese modern art", modern giant landscape painters as Zhang Daqian, Pan Tianshou etc., all absorbed nutrients from Shitao's landscape paintings. Shi Tao's creative theory and creation practice, still had the infinite charm to inspire future generations.

Pan Tianshou is a famous modern Chinese painting master. His "not accidental in a short duration of time" artistic achievement was the result of "search every lofty peaks for draft". Pan Tianshou had very high comments on Shi Tao's paintings and theories. From rocks wrinkle points in his landscape paintings we can see the traces of his learning from Shitao.

Li Keran is a modern famous Chinese painting. He was another peak of Chinese painting history after Qi Baishi and Huang Binhong. Because Li Keran went the same way of Shi Tao "search every lofty peaks for drafts", and understood the fundamental essence of painting theory of Shi Tao "search every lofty peaks for drafts".

Shi Tao painting theory in the present sense is that painting should follow the times; search the scenes of nature for their own use. The accumulation of art from continuous learning and exploration, not only from "body" and "heart" in-depth practical life continue to practice and hone, digest, convergence and precipitation. In the process of painting creation, the road is far away, which needs to study and capture. The true meaning of search every lofty peak for draft is not only we understand from the literal as accumulation of painting materials, but also refers to the creation concept that the painter and the nature as a whole in the process of painting.

\section{Summary}

When we search every lofty peaks for draft, for the beautiful natural scenes, can use advanced things so as to gain painting materials. But the key things should use the hands to record the feelings at the time, in order to accumulate creation feeling. Painting has always been an important way and means to guide the painter to imagine. The things that have been viewed by the artist have been painted. To find out the fine things in nature, you need to watch carefully.

\section{Conclusion}

Thanks to my paper advisor, the paper's arguments and thesis could not be without your careful guidance; thank the students' help for me in the four years. From the selection of subjects to the end, in this period of time had a too much laughter and tears, there were happiness for affirm my ability, but also shame on lack of knowledge, after months of unremitting efforts, finally completed my graduation paper, thank you again for professional teacher and advisor careful guidance and care for me. Finally, send my most heartfelt thanks and great respect for my alma mater and the whole department of teachers who cultivated me in the four years. 


\section{References}

[1] Yang Chengyin, Shi Tao. Beijing: Chinese Renmin University Press, 2009

[2] Huang Jian. Chinese landscape painting as mirror - Search every lofty peaks. Shanghai: Shanghai painting and calligraphy press, 2006

[3] Yang Huidong, four monks' painting at the beginning of Qing Dynasty. Tianjin: Tianjin people arts press, 2005

[4] Shan Guoqiang. China art history Ming and Qing Dynasties to modern times. Beijing: Chinese Renmin University press, 2014

[5] Luo Guanzhong. I read the record of Shitao drawing theory. Beijing: Rongbaozhai press, 1996

[6] Han Linde. Shitao biography. Nanjing: Nanjing University press, 2011

[7] Shi Tao, the record of Shitao drawing theory. Xileng press, 2006

[8] Zhang Shuheng. four monks' painting art at the beginning of Qing Dynasty. Huhehaote: Yuanfang press, 20 